\title{
Edukasi Penggunaan Obat Saat Bulan Ramadhan Ditinjau dari Kesehatan dan Kaidah Islam di Lingkungan Warga Aisyiyah Kota Palangka Raya
}

\author{
Education on the Use of Medicines during Ramadhan in Terms of Health and Islamic Principles \\ in the Citizens of Aisyiyah, Palangka Raya City
}

Rabiatul Adawiyah*
Agustinawati Umaternate
Risqika Yuliatantri
Paramawidhita
Department of Pharmacy, Universitas
Muhammadiyah Palangkaraya,
Palangka Raya, Central Kalimantan,
Indonesia
*email: abi.ubiet@gmail.com
Kata Kunci
Penggunaan Obat
Puasa
Ramadhan
Keywords:
Medication Use
Fasting
Ramadhan
Received: September 2019
Published: December 2019

\begin{abstract}
Abstrak
Puasa diartikan sebagai ibadah menahan diri atau berpantang makan, minum, dan segala hal yang membatalkannya, dimulai dari terbit fajar sampai terbenam matahari. Meskipun wajib, puasa memiliki rukhsah (keringanan) yakni dapat dibatalkan, misalnya pada kondisi-kondisi yang dapat membahayakan keselamatan jiwa atau kesehatan jika puasa diteruskan. Umat muslim yang menjalani puasa dapat memiliki latar belakang kondisi medis yang berbeda-beda, misalnya pasien dengan hipertensi, diabetes melitus, ulkus peptikum, gastroesophageal reflux disease, inflammatory bowel disease, penyakit paru, penyakit jantung, penyakit ginjal, dan kehamilan. Oleh karena itu, pengetahuan mengenai puasa dan dampak nya terhadap berbagai kondisi medis. Tidak banyak orang yang mengerti betul tentang aturan pakai obat saat berpuasa sehingga terapi tidak berjalan dengan baik. Padahal penyakit yang tidak terobati dengan benar akan mengacaukan puasa kita.Solusi yang ditawarkan yaitu dengan adanya kegiatan pengabdian ini dapat memberikan pemahaman kepada warga Aisyiyah kota Palangka Raya tentang cara penggunaan obat di bulan Ramadhan dari segi ilmu kesehatan dan dari segi kaidah Islam.
\end{abstract}

\begin{abstract}
Fasting is defined as worship holding back or abstaining from eating, drinking, and all things that cancel it, starting from dawn to sunset. Although obligatory, fasting has rukhsah (relief), which can be withdrawn, for example, in conditions that can endanger the safety of life or health if fasting is continued. Muslims who undergo fasting can have different medical conditions, for example, patients with hypertension, diabetes mellitus, peptic ulcer, gastroesophageal reflux disease, inflammatory bowel disease, lung disease, heart disease, kidney disease, and pregnancy. Therefore, knowledge of fasting and its effects on various medical conditions. Not many people understand very well about the rules of using drugs when fasting so that therapy does not go well, whereas illness that is not appropriately treated will disrupt our fasting. The solution offered is the existence of this service can provide an understanding to the citizens of Aisyiyah in the city of Palangka Raya about how to use drugs in the month of Ramadan in terms of health science and terms of Islamic principles.
\end{abstract}

(C) 2019 Rabiatul Adawiyah, Agustinawati Umaternate, Risqika Yuliatantri Paramawidhita. Published by Institute for Research and Community Services Universitas Muhammadiyah Palangkaraya. This is Open Access article under the CC-BY-SA License (http://creativecommons.org/licenses/by-sa/4.0/). DOI: https:// doi.org/10.33084/ pengabdianmu.v5i1.1093.

\section{PENDAHULUAN}

Puasa diartikan sebagai ibadah menahan diri atau berpantang makan, minum, dan segala hal yang membatalkannya, dimulai dari terbit fajar sampai terbenam matahari (Kastolani, 2016). Dalam agama Islam, dikenal dua jenis puasa, yaitu puasa wajib (puasa Ramadhan) dan puasa sunnah (misal puasa Senin- 
Kamis). Puasa yang dimaksud dalam tulisan ini adalah puasa Ramadhan. Puasa Ramadhan merupakan ibadah wajib bagi seluruh pemeluk agama Islam, akil baligh, dan sehat (Andy, 2018). Pengalaman berpuasa, mengajarkan setiap muslim kedisiplinan, pengendalian diri, dan mendidik kepedulian pada mereka yang tidak mampu (Dermawan, 2013). Selama puasa Ramadhan, mayoritas umat muslim akan memiliki dua waktu makan, yakni segera saat tenggelamnya matahari yang ditandai dengan masuknya waktu sholat maghrib (dikenal dengan istilah ifthar atau berbuka puasa) dan makan saat sebelum fajar terbit (dikenal dengan istilah sahur), sehingga lamanya waktu berpuasa adalah berkisar antara 11 jam hingga 18 jam setiap harinya (Azizi, 2002; Azizi, 2010).

Puasa Ramadhan berbeda sudut pandang fisiologis dan psikologisnya dibandingkan puasa guna kepentingan penelitian (Alfin et al., 2019). Mereka yang menjalani puasa Ramadhan, sejatinya tidak hanya menahan diri dari makan dan minum, namun juga menjaga pikiran dan seluruh panca indranya dari perbuatan yang dapat mengurangi amalan puasa (Firmansyah, 2010). Oleh sebab itu, perubahan fisiologis pada mereka yang menjalani puasa Ramadhan dapat berbeda dari mereka yang berpuasa sebagai sukarelawan penelitian (Azizi, 2010). Sejatinya, puasa tidak dimaksudkan untuk menyulitkan dan mencelakakan individu muslim. Secara tegas, dalam Al-Quran dijelaskan bahwa berpuasa tidak diwajibkan pada anak-anak, perempuan dalam masa menstruasi, orang sakit, orang yang dalam perjalanan, perempuan hamil dan menyusui (Firmansyah, 2010). Meskipun wajib, puasa memiliki rukhsah (keringanan) yakni dapat dibatalkan misalnya pada kondisi-kondisi yang dapat membahayakan keselamatan jiwa atau kesehatan jika puasa diteruskan. Umat muslim yang menjalani puasa dapat memiliki latar belakang kondisi medis berbeda-beda. Seseorang yang membutuhkan pengobatan pada bulan ramadhan akan meminta saran kepada tenaga kesehatan terkait apakah mereka dapat berpuasa pada keadaan terebut(Alfin et al., 2019). Hal penting adalah bahwa peranan tenaga kesehatan bukan sebagai penentu atau pemberi fatwa apakah seseorang pasien boleh berpuasa atau tidak. Keputusan akhir berpuasa atau tidak, dikembalikan kepada pasien sendiri (Subrata \& Dewi, 2017).

Aspek-aspek kesehatan berkaitan dengan puasa Ramadhan dan implikasinya pada beberapa kondisi penyakit yang kerap dijumpa idalam praktik sehari-hari, seperti masalah saluran cerna, penyakit jantung, diabetes melitus, hipertensi, penyakit ginjal kronik, asma, kehamilan dan lain-lain (Firmansyah, 2010). Jika pemakaian obat yang dilakukan oleh masyarakat tidak tepat, dikhawatirkan kualitas pengobatan akan menurun dan tujuan pengobatan tidak akan tercapai. Dosis obat yang tidak benar akan mengakibatkan obat tidak poten atau bahkan dapat menimbulkan efek toksik bagi tubuh (Gitawati, 2008). Pada bulan Ramadhan, akan terjadi perubahan pola waktu makan. Demikian juga dengan waktu mengkonsumsi obat harus disesuaikan. Untuk pemakaian obat yang harus diminum setiap 6 atau 8 jam, penggunaannya harus disesuaikan agar pengobatan pasien tidak terganggu, namun pasien tetap dapat menjalankan ibadah puasa (Natalia \& Sulistyaningsih, 2018).

\section{METODOLOGI}

Pengabdian kepada masyarakat ini dilaksanakan pada awal bulan ramadhan (Mei) di Jl. Pangeran Samudera IV Palangka Raya bertempat di salah satu rumah ibu warga Aisyiah dan Mesjid Darul Arqom Komplek Universitas Muhammadiyah Palangkaraya.

Sasaran pengabdian kepada masyarakat ini adalah ibuibu warga Aisyiah kota Palangka Raya. Metode pengabdian ini dilaksanakan dengan cara sosialisasi, 
diskusi dan monitoring yaitu dengan terlebih dahulu pemaparan materi dari tim dosen yang terdiri dari Rabiatul Adawiyah, S.Farm., M.Si., Apt.; Dra. Hj. Agustinawati Umaternate, M.Si., Apt.; serta Risqika Yuliatantri Paramawidhita, M.Farm. (dari segi kesehatan) yang didampingi oleh Apoteker Agent of Change/AOC dari Kota Palangka Raya, beserta pemaparan materi dari Dr. Asep Solikin, MA. (dari segi kaidah islam), dan dilanjutkan dengan diskusi aktif sesi tanya jawab. Untuk monitoring dilakukan setelah sosialisasi berguna untuk meninjau apakah di aplikasikan selama bulan ramadhan.

\section{HASIL DAN PEMBAHASAN}

Kegiatan ini didukung oleh warga Aisyiyah baik dari pengurus wilayah maupun pengurus daerah Kota Palangka Raya dan Universitas Muhammadiyah Palangkaraya. Serta Pengurus Cabang Ikatan Apoteker Indonesia kota Palangka Raya (Apoteker Agent of Change/AOC). Kegiatan pengabdian kepada masyarakat mengenai “Edukasi Penggunaan Obat Saat Bulan Ramadhan Ditinjau Dari Kesehatan Dan Kaidah Islam Di Lingkungan Warga Aisyiyah Kota Palangka Raya" memiliki banyak manfaat. Dimana latar belakang pendidikan dan pengetahuan ibu-ibu yang tergabung di dalam kegiatan tersebut beragam, sehingga informasi penggunaan obat selama bulan Ramadhan tidak semua memahami secara baik dan benar dari segi kesehatan dan kaidah islam. Dengan terlaksananya kegiatan tersebut warga Aisyiyah Kota Palangka Raya menerima dengan sangat positif dan menyambut baik kegiatan tersebut untuk dilaksanakan di lingkungan mereka. Dokumentasi dari tim kegiatan Pengabdian yang terlibat disajikan pada Gambar 1.

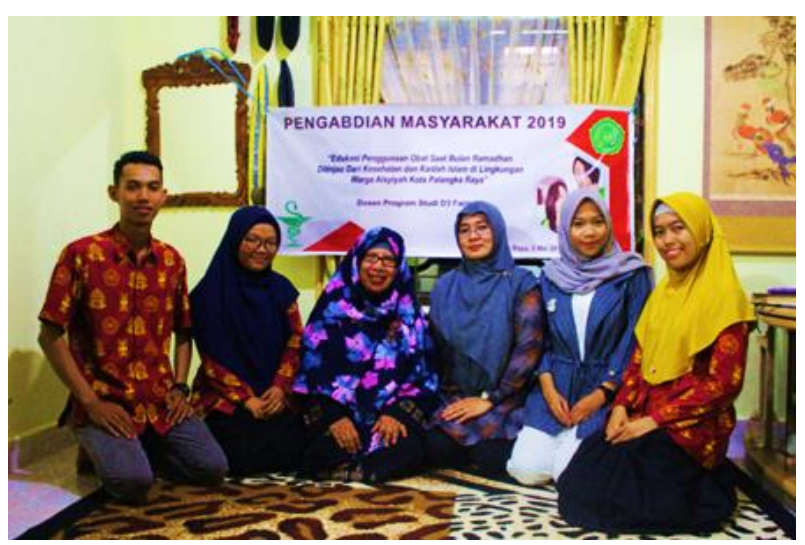

Gambar 1. Tim Dosen beserta mahasiswa pendamping saat kegiatan sosialisasi

Secara umum, kegiatan terlaksana dengan sangat baik. Sesi diskusi yang dibuka berjalan dengan menarik ditandai banyaknya feedback yang diberikan oleh peserta kegiatan sosialisasi tersebut, tidak jarang hingga menimbulkan interaksi yang menarik dan melibatkan banyak peserta. Beberapa dokumentasi pada saat kegiatan pengabdian kepada masyarakat yang dilakukan dari sosialisasi pemaparan materi dan saat monitoring tersaji pada Gambar 2 sampai Gambar 7.

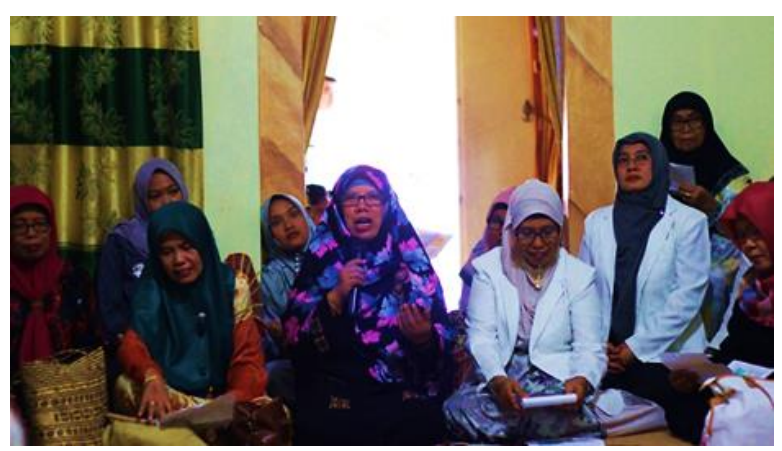

Gambar 2. Sesi pemaparan materi

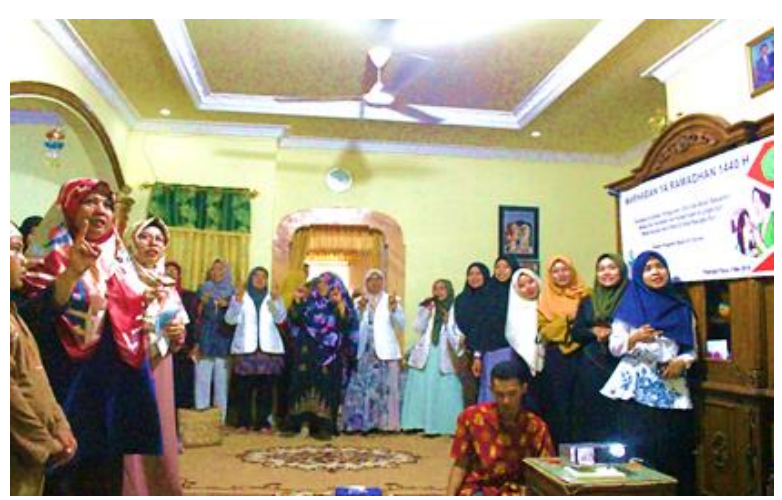

Gambar 3. Suasana pada saat pemaparan materi 


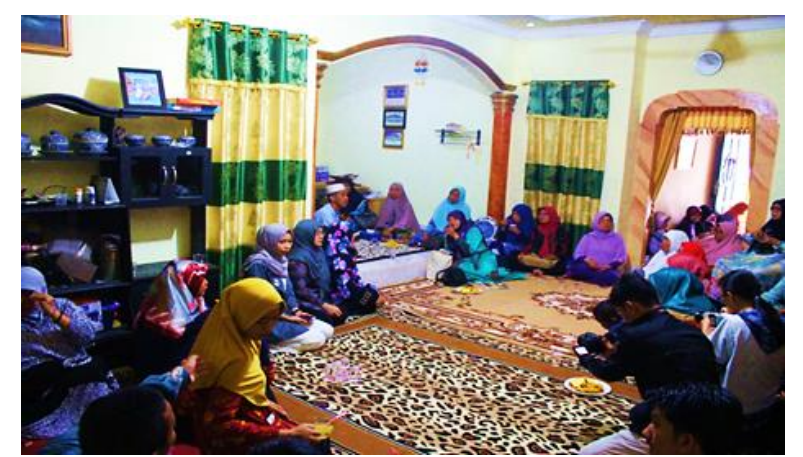

Gambar 4. Sesi pemaparan materi segi kaidah Islam

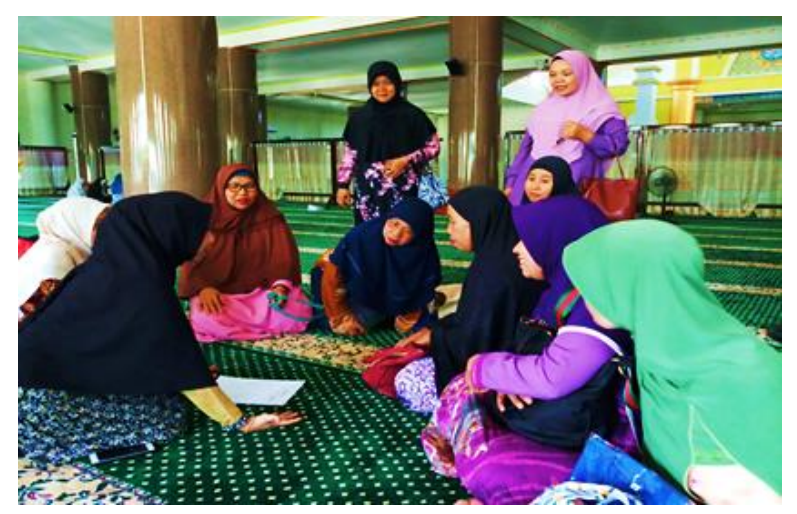

Gambar 5. Monitoring warga Aisyiyah

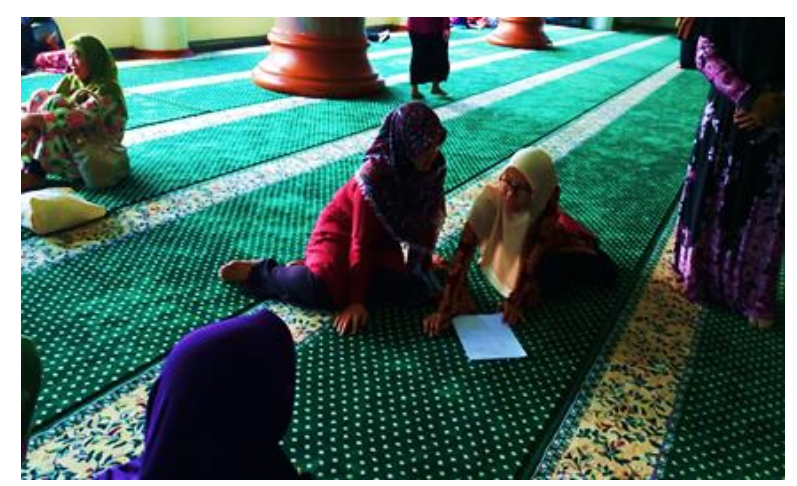

Gambar 6. Monitoring warga Aisyiyah

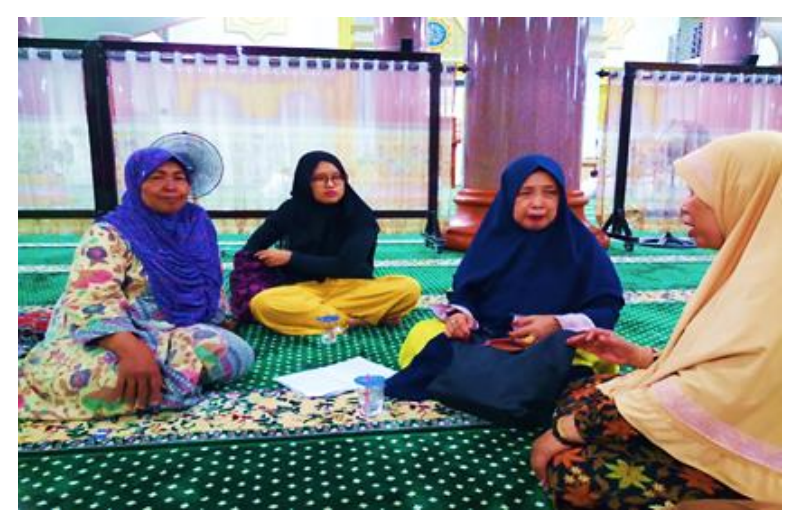

Gambar 7. Monitoring warga Aisyiyah

\section{KESIMPULAN}

Berdasarkan kegiatan pengabdian masyarakat yang dilaksanakan di lingkungan warga Aisiyah Kota Palangka Raya berjalan sesuai dengan rencana yang tertera di jadwal dan mendapatkan informasi serta pengetahuan yang baik bagaimana cara mengkonsumsi obat yang baik dan benar berdasarkan ilmu kesehatan dan kaidah islam. Berdasarkan hasil evaluasi yang telah dilaksanakan dapat diberikan saran berupa adanya kegiatan lanjutan pengabdian masyarakat mengenai penggunaan obat khusus secara Lima O

\section{UCAPAN TERIMA KASIH}

Terima kasih kepada LP2M Universitas Muhammadiyah Palangkaraya atas bantuan dana pengabdian yang bersumber dari APBU Universitas Muhammadiyah Palangkaraya Tahun 2019 dan fasilitas yang disediakan oleh pihak Mitra.

\section{REFERENSI}

Alfin, R., Busjra, Azzam, R. 2019. Pengaruh Puasa Ramadhan Terhadap Kadar Gula Darah Pada Pasien Diabetes Mellitus Tipe II. Journal of Telenursing $\quad$ (Joting). 1(1):191-204. https://doi.org/10.31539/joting.v1i1.499

Andy, S. 2018. Hakikat Puasa Ramadhan dalam Perspektif Tasawuf (Tafsir Q.S Al-Baqarah: 183). Ibn Abbas: Jurnal Ilmu Alquran dan Tafsir. 1(1):1-17. http://dx.doi.org/10.9876/jia.v1i1.1895

Azizi, F. 2010. Islamic fasting and health. Annals of Nutrition and Metabolism. 56(4):273-282. https://doi.org/10.1159/000295848

Azizi, F. 2002. Research in Islamic fasting and health. Annals of Saudi Medicine. 22(3-4):186-191. https://doi.org/10.5144/0256-4947.2002.186

Dermawan, O. 2013. Pendidikan Karakter Siswa Melalui Ibadah Puasa. Edukasia: Jurnal Penelitian $\begin{array}{lll}\text { Pendidikan } & \text { Islam. }\end{array}$ 
http://dx.doi.org/10.21043/edukasia.v8i2.75

2

Firmansyah, M.A. 2010. Pengaruh Puasa Ramadhan pada Beberapa Kondisi Kesehatan. CDK (Cermin Dunia Kedokteran). 42(7):510-515.

Gitawati, R. 2008. Interaksi Obat Dan Beberapa Implikasinya. Media Penelitian dan Pengembangan Kesehatan. 18(4):175-184.

Kastolani. 2016. Ibadah Ritual Dalam Menanamkan Akhlak Remaja. INJECT: Interdisciplinary Journal of Communication. 1(2):127-144. https://doi.org/10.18326/inject.vli2.127-144

Natalia, A. Sulistyaningsih. 2018. Review Artikel: Puasa Ramadhan Dan Diabetes Melitus. Farmaka. 16(1):331-336.

https://doi.org/10.24198/jf.v16i1.17498

Subrata, S.A., Dewi, M.V. 2017. Puasa Ramadhan Dalam Perspektif Kesehatan: Literatur Review. Khazanah: Jurnal Studi Islam dan Humaniora. 15(1):235-256.

http://dx.doi.org/10.18592/khazanah.v15i2. 1139 